\title{
What is 'Humanistic' About Humanistic Management?
}

\author{
Clause Dierksmeier ${ }^{1}$
}

Received: 21 January 2016 / Accepted: 2 April 2016 / Published online: 28 July 2016

(C) Springer International Publishing 2016

\begin{abstract}
Presently it is en vogue to search and research business models heedful to concerns of social, moral, and ecological sustainability. On the view here defended, however, we ought not to strive for piecemeal corrections but for a thoroughgoing paradigm change of the predominant economic theories and practices in favor of a genuinely 'humanistic management.' This very call for humanistic management serves as an introduction into this paper (section 1). The article then lays out a concept of humanistic management in three methodologically distinct steps, description - ascription - prescription, before addressing potential challenges to the approach of humanistic management and, finally, pointing out some of its practical implications. The article hence proceeds as follows: From a critique of the reductionist description of economic agency given in conventional economics (2), the paper moves on to the ascription of freedom and responsibility by and through human actors (3), which appears essential for any attempt at re-integrating moral prescriptions into economics and, by extension, management theory (4). The resultant, dignity-centered humanistic management conception is then defended against challenges from postmodern authors and defendants of 'deep ecology' (5). Afterward, the article presents some normative postulates for management practice (6); last, the main findings of the paper are summarized (7).
\end{abstract}

Keywords Freedom · Responsibility · Business ethics · Corporate social responsibility · Management theory $\cdot$ Economics $\cdot$ Freedom $\cdot$ Liberty $\cdot$ Homo economicus $\cdot$ Humanistic management

\section{Introduction: The Call for Humanistic Management}

Many of the multiple crises human kind faces at the dawn of the 21st century share a common denominator: an economic system with only marginal regard for human values and virtues. On close inspection, the patent disregard for moral norms in business and the economy appears

Clause Dierksmeier

dierksmeier@weltethos-institut.org

1 Weltethos-Institut (Universität Tübingen), Hintere Grabenstraße 26, 72070 Tübingen, Germany 
less an outcome and much more a cause of its disruptions and system failures. Having removed a concern for moral values from the center of economic thinking and having thus ostracized ethical considerations to the margins of business practice, past management education contributed to the social and ecological problems of today (Ghoshal 2005). Also management lore has it that businesses are to pursue their own interests and governments, by imposing legal constraints, shall assume responsibility for the rest of society (Friedman 1970), the relation between societal and entrepreneurial interests presents itself differently nowadays. In ever fewer countries, governments alone are in a position to guarantee the requisite preconditions for both society and businesses to thrive (Streeck 2013). Governments have become weaker, multinational corporations stronger, and consequently the overall impact of socially or ecologically unsustainable business models is much more felt. The biological and cultural ecologies of business are simply no longer robust enough to absorb business models solely based on financial value extraction (Hart 2005).

Managers everywhere are contemplating anew their own role in business and society. Incentivized to focus on one-dimensional success metrics, they are suddenly charged to display multi-dimensional perspicuity. Once trained and hired for short-term performance measurement, CEOs are now asked to ponder the long-term consequences of their actions and omissions. Educated to reduce complexity, executives are now being tasked to embrace it. Past are the days where they were lauded for smartness and service to shareholders alone, today businesspeople are seen as responsible to a wide array of stakeholders (Werther and Chandler 2005; Freeman et al. 2007). Societies increasingly demand that managers procure more than pecuniary gains and create real value (Spitzeck et al. 2009).

A search is underway for a new conceptual framework for business in general and for the theory of the firm in particular. The respective spectrum reaches from more moderate suggestions in the field of stakeholder theory (Freeman et al. 2004) to more radical voices in the fields of critical management studies (Fournier and Grey 2000; Parker 2002) and heterodox economics (Colander 2000; Colander et al. 2004; Mearman 2011; Dequech 2007). Especially new and hybrid forms of business practices are being studied, which do not follow a purely commercial logic alone but are best described through social enterprise models (Melé and Dierksmeier 2012).

As an attempt to integrate the diverse approaches for a more life-conducive economy and for responsible corporate practices, theories of humanistic management advocate a paradigm shift in business theory as well as in management practice. In the field of theory, they suggest a transition from mechanistic economics towards humanistic economics (Dierksmeier 2011), so as to move, in practice, away "from capitalistic to humanistic business" (Pirson et al. 2014).

The old consensus that the social responsibility of business is but to comply with legally and perhaps also ethically imposed side-constraints on how it pursues its bottom line goals, is no longer legitimate. Instead, the top line of business itself is at issue, and with it the objective function of business itself is under discussion. The debate to be had thus touches upon the very axioms of management theory and upon the economic theories that inform it. (Pirson and Lawrence 2010; Gladwin et al. 1995). It becomes ever more evident that we need to challenge the mental models of conventional economics (Dierksmeier 2011). Economics, as any social science, views reality through certain theoretical lenses that influence its perception of its subject matter, i.e. of business and the economy. The enhanced precision each such lens grants us comes at a price, though. Cognitive lenses, like any other, only improve our perception of certain aspects of reality. Other aspects, more at the margin than in the center of the focus of the selected lens, become blurred; and beyond its scope the selected lens cannot capture anything 
at all. Hence, using only one lens at a time typically leads to over-simplification: purchasing a false clarity at the cost of omitting important alternative views. The more complex the studied topic, the more variegated should be the lenses we apply, and the more careful we must select them. Where the subject matter in question is human economic behavior and conduct in business affairs, the investigative methods employed should be humanistic, not mechanistic, or so I shall argue.

\section{Description: Reasons of Freedom Rather Than Laws of Necessity}

All responsibility presupposes freedom, and corporate responsibility makes no exception; the demand for corporate responsibility - on behalf of any normative goal - requires managerial freedom to deviate from maxims of sheer profit-maximization in favor of other objectives. The practical realization of such responsibility is however premised on the theoretical realization of the factual as well as potential freedoms of management to pursue alternative courses of action. Chances unseen are, after all, chances unused. For any normative approach to business whatsoever, the topic of managerial freedom is consequently of central importance (Dierksmeier 2011).

Yet the mechanistic nature of neoclassical economics, where corporations are portrayed as 'machines' for profit-maximization, subject to iron laws of competition, seems wholly impervious to considerations of free agency (Brodbeck 2013). Conventional economics lives off a quantitative vocabulary and follows a mathematical grammar. Economic actors, within this linguistic scheme, are portrayed as in pursuit of managerial objectives which ideally, albeit not always factually - could be advanced by replacing human judgment by algorithms. Leeway in managerial decision-making consequently appears to be something that - in favor of optimal performance - ought to be reduced to zero. As a result, in standard economic theory, managerial freedom is not viewed positively as an intellectual space for the exercise of responsibility, but negatively as something that, for the time being, cannot quite be eliminated; a tribute reluctantly paid - theoretically - to the uncertainties of a still imperfect economic science and - practically - to the vagaries of human factors in business.

How did this image of business come about? Is it the rule or rather the exception in the intellectual history of economics? Glancing back at the records of economic thought we find: From Aquinas (Dierksmeier and Celano 2012) to Adam Smith (Hühn and Dierksmeier 2014), i.e. for about several thousand years, economic thinking was firmly linked to metaphysical, theological, and moral reflections. Although after Adam Smith, economic philosophy (then under the name of national or political economy) emancipated itself from theology, it too did remain oriented at the ideal of the common good, to be defined by national political systems (Brodbeck 2013).

Throughout the ages, that is, and up until the late 19th century, qualitative ends oriented the economic discourse. They defined the understanding of subjective wellbeing and objective welfare, and how either should be pursued. Only in the last 200 years, a drift occurred that brought about the contemporary outlook of economics, where now a self-imposed restriction to quantitative analysis predominates (Dierksmeier 2011). In an effort to become just as 'scientific' as their colleagues in the natural sciences, economists of the late 19th century began to cut their discipline off from the social and political sciences and allied themselves with the methodological apparatus of physics and mathematics (Wieser 1884). 
Trying to analyze economic problems 'purely', i.e. without resorting to extrinsic values, ever more economists looked to the mathematical models of physics, especially mechanics, in search of a new paradigm (Walras 1909). The enormous success that the discipline of mechanics celebrated after the publication of Joseph Luis Lagrange's Mécanique analytique (1788) inspired John Stuart Mill (1806-1873), Auguste Comte (1798-1857) and numerous others to describe economic structures as quasi-mechanical laws (Dierksmeier 2011).

While mathematical mechanics gave the new paradigm its formal aspect, utilitarianism contributed the material side, with the effect that the entire discipline of economics was recast as a "mechanics of utility and self-interest" (Jevons 1871, 90). The utilitarian contribution had come from Jeremy Bentham (1748-1832) and James Mill (1773-1836). From dissatisfaction about the seemingly endless quarrels of metaphysics over the salient norms of political and economic decisions, they decided to subjectivize the realm of values hitherto believed to be objective. Instead of probing 'human nature' or the 'moral law' what would be right for everyone, they asked what would benefit given individuals. Utilitarians ventured one could achieve consensus on overall welfare, simply if one measured what people actually appreciated, instead of ranking what they ought to value. Thus began the notion of aggregate interest to replace the idea of the common good (Spiegel 1971, 341-343).

In order to make utility theory fit for mathematical treatment, William Stanley Jevons (1835-1882) changed Bentham's definition of utility as a function of an (immaterial) increase in personal happiness into denoting "the abstract quality whereby an object serves our purpose, and becomes entitled to rank as a commodity" (Jevons 1871, 44-45). Inspired by the thus conceivable 'materialization' of utility into a function of (readily quantifiable) commodity consumption, Jevons set out to "treat the Economy as a Calculus of Pleasure and Pain" (ibid., VII), wherein human motives factor in merely "as positive and negative quantities" (ibid., 38).

Freed from the intricacies of qualitative evaluations of economic goals and purposes, the vexing problem of societal utility optimization was translated into the simpler one of a quantitative maximization of commodity consumption. Later changes in the utility concept such as Alfred Marshall's move away from commodity consumption towards the willingness to pay for goods (Marshall 1890, 15-16) did not change too much in the outcome: Economics had operationalized (moral) concerns of 'better' versus 'worse' into a (technical) calculus of 'more' over 'less'.

This turn to a subjectivist value theory in England joined forces with an important move within Austrian economics towards the theory of 'marginal utility', spearheaded by the works of Carl Menger (1840-1921). Menger also moved from substantial value estimates towards procedural assessments (expressed in prices), which reinforced the utilitarian turn from objective to subjective value theories (Hayek 1952, 256). Only by discarding the notion of objective values, Menger believed, conceptual confusions could be avoided (Menger 1871, 86) and economics had a chance to become an exact science based, like any other, on natural laws (ibid., 8).

The relevance of these methodological shifts becomes patent by way of comparison: Up to and including Adam Smith, economic theories operated with the notion of objective values. They did not only aim to describe reality but also dealt with it prescriptively, with a view to correct aberrant subjective evaluations. On the contrary, theories which generate the value of given commodities from their subjective appraisals in exchange relations do not establish any such critical distance to their objects. The prescriptive and counterfactual use of economic value theory then collapses.

These implicit consequences of the subjectivist turn of economics were made explicit in in the early years of the 20th century (Backhaus 2000). In prolonged controversies, German 
economists and social scientists debated the proper role of value judgments ("Werturteile") in economics. Especially Max Weber (1864-1920) and Werner Sombart (1863-1941) fought over the question whether the discipline of economics should also contain critical and prescriptive elements. Ultimately, Weber's view that economics must not evaluate the goals of economic activity prevailed; the discipline was to confine itself to describing how the economy worked, and leave its normative assessment and prescriptive transformation to politics (Weber 1904; Weber 1918).

Values being ostracized, economists committed themselves to what was left: determining the most intelligent use of scarce resources for given goals. Embracing the idea of normative neutrality and versatile utility, this is the import of Lionel Robbins' canonical formulation: "Economics is the science which studies human behavior as a relationship between ends and scarce means which have alternative uses" (Robbins 1932, 16). Economics had, in short, become a value-free, positivistic science, whose policy advice rested in hypotheticals: If a community wanted certain goods, then economists were to examine how to achieve these in the most cost-effective way (Friedman 1953). Up to date, this refusal to discuss the appropriate (individual and social) objectives of economic activity is being staunchly defended (Lucas 1988). Economics continues to rely on testing its theories in merely quantitative terms and qualitative value judgments are shunned (Stigler and Becker 1977).

Admittedly, economists of the 20th century have updated their linguistic arsenal. Instead of old-school Newtonian physics and its mechanical imagery, thermodynamics and entropy laws are now the metaphors en vogue. Such emulations of the latest science lingo are, however, no less hobbled by the general problem afflicting any transfer of methods and metaphors from the natural sciences onto the human behavior: Obfuscating "that its subject-matter is living and free men" (Pigou 1962, 9), who make up their own minds before responding to outside stimuli, the physicalism of economics invites a variety of explanatory errors.

Economic prognosis is a case in point. In economics, prognoses are an eminently selfinfluencing phenomenon (Schumpeter 1954), not only on stock markets. While in physics an influence of the observer and/or of the observation on the observed (while playing a role on a quantum level) can be neglected for the entire Newtonian realm of physics, feedback-loops between theory and practice are a standard, even constitutive phenomenon in the economic realm (McCloskey 1994). Human beings form theories about their contexts and act not simply driven by internal or external material causes but upon the interpretations they make of their life-worlds.

Hence, the mechanistic paradigm entraps the mind in a vicious circle: Defining - first economics as a merely quantitative science, its proponents - second - exclude from its domain all objective values (as they are not readily quantified), and - third - conclude that the counterfactual dimension of values is unscientific, wherefore it - fourth - would be illegitimate to engage the economic discipline in morally scrutinizing individual values and choices ('ends'), which - fifth - helps justify the current focus in economic research solely on the maximization of utility (through 'means') that - sixth - explains the predominance of quantitative over qualitative categories in economics; quod erat demonstrandum.

These constructions bear only slight resemblance with reality. There is no such thing as 'the economy' or 'the market' outside time and space. Economic activity takes place at certain locations, in ever varying forms, subject to diverse cultural values and political influences. Consequently, to abstract from all such imports is sorely mistaken. Due to the holistic nature of various socio-economic phenomena, any overly segmented analysis is bound to keep out truly causal factors and so to ascribe causality to what are, actually, irrelevant, albeit contiguous 
phenomena. When change occurs in several social sub-systems at once, more comprehensive (qualitative, normative, hermeneutical) perspectives on 'all things changed' prove therefore superior to the ceteris paribus-('all other things equal')-assumptions of mechanistic thinking.

The salient point here - the critique of 'atomizing' the elements of economic theory - refers back to yet another debate between German economists, the "Methodenstreit" between Carl Menger and Gustav von Schmoller (1838-1917). At issue was the epistemic significance of inductive and deductive methods (Bostaph 1978). For the more inductively oriented 'historical school', context co-defines the content of concepts so that the assumption of an absolute economic truth beyond time and space makes little sense (Schmoller 1883). Economists have to base their theories on statistical and other forms of observation in order to view economic processes 'holistically', i.e., together with the constellations wherein they are embedded (Schmoller 1893). On the contrary, the 'axiomatic' or 'isolationist' approach supposes that through conceptual work one can ultimately arrive at the 'simplest' elements and thus at the true 'essence' of economic reality, from where then to reveal by logical deductions further economic truths - of absolute epistemic status (Menger 1883). This method was meant to provide the causally explanatory part of economics, relegating all observational methods to a secondary, merely illustrative status.

The lure of Menger's promise of exactitude and certainty won the day. Never since did the 'historical schools' - which at the time of the controversy were predominant - regain their former standing in the discipline. When economic laws, however, are being deduced from axiomatic assumptions about economic agents and markets, without taking account of inductively gained empirical information about these agents and markets, one is prone to misjudge either: Forgetting that free human beings are the factors behind economic facts, one projects the very rigidity of our method onto individuals and society, perceiving them as subjected to unalterable laws.

But human notions and ideals influence the structures of economic behavior. As more inductively oriented economists have shown time and time again, with an alteration in human attitudes changes economic behavior, - eroding many an allegedly eternal economic 'law'. Our freedom and the ideas about its responsible use do play an eminent role in the economy (Nguyen 2000), - albeit one that certain economic methods cannot adequately conceptualize.

The methodological constructs used by conventional economics are hence by no means innocent devices. Whenever extra-economic or non-quantifiable factors affect the economy, each method blocking out such factors as irrelevant, leads to false conclusions for economic policy and business practice. A solely deductive approach to markets, for example, based, as it is, on assumptions of perfect information, perfect competition, perfect rationality, etc. will typically establish that markets are nothing but transaction chambers for human freedom, neutral to any and all human aspirations. In this logic, their outcomes will appear as but the congealed result of free choices and mutually beneficial exchange: spontaneously established liberal orders of all-around fairness and reciprocal utility. Any interference would hence be as ineffective as it would be illegitimate (Waligorski 1990).

Overlooked is thus that market economies, under real conditions, favor the exchange of easily 'marketable' goods and services. Commodifiability limits practically the entry of products into the market economy as much as quantifiability restricts theoretically the entry of concepts into economics. Their purported neutrality notwithstanding, both market economies and market economics have hence a strong systematic bias in favor of exchangeable and against non-substitutable goods (diZerga 1997). The less, however, economics recognizes itself as shaping the reality it observes through its descriptions, the less sensitive to the social consequences of its advice its proponents tend to be (Galbraith 1986, 403). 
The professed neutrality of economics, although unbendingly defended, is an illusion (Ulrich 2008). Even when economics forfeits explicit (categorical) orientations, it still has to employ implicit (hypothetical) orientations. Else economists could neither unite all the subdisciplines of their science under a common research perspective, nor formulate any tangible recommendations. Economics, simply put, needs a common denominator of what it considers as micro-economic and macro-economic success. When economic reasoning no longer aims to guide the qualitative direction of economic ends, economic rationality will, by default, turn to maximize the utmost quantity of employable means. Imperceptibly at first but at last quite markedly, economics thus arrived at ascribing to individual economic agents and to economies as a whole a preference of 'more' over 'less', defining all economic agency as 'maximization behavior' (Samuelson 1947). That is, by rejecting any and all qualitative standards, the positivistic posture of contemporary economics has ushered in quantitative growth as the overarching goal of all economic activity (Friedman 1953). So can removing the qualitative and normative objectives from economics surreptitiously drive a "progress toward the wrong goals" (Galbraith 1986, 409).

Instead of continuing to hold fast to the elusive ideal of value-free science, we should rather concentrate on the values intrinsic to any and all scientific research (Douglas 2009). The processes and procedures of science itself are, after all, quite value-laden: From problemselection to the choice of hypotheses and methods, values (determining what is pertinent, which criteria establish truth in an unbiased way, etc.) play an immense role in research. In short, the "scientist qua scientist makes value judgments" (Rudner 1953). In the interest of democratic accountability, therefore, economists should not try to hide the implicit valuedimensions of science from the public but rather explicate them so that they can be openly debated and criticized (Douglas 2009, 70-73). We need to recast economics as a self-reflective social science and emphasize the importance of qualitative aspects, critical self-evaluations, and moral values for the discipline (Boudling 1969).

In sum, emphasizing pseudo-necessities and downplaying real freedoms, economic theory has obfuscated the true reach of individual and collective autonomy in business affairs. The methodological reductionism of economics induced an under-complex perception first and an inept management second of socio-economic realities: For lack of an intellectual realization of the import of responsible freedom on human action, its practical realization in acts of free responsibility failed to transpire. Let us, instead, center economics on the authentic human condition, on real human beings and on their actual relations. As the self-ascription of the human being as both free and morally responsible belongs to any and all human orientation in practice, it must also inform the description of economic agency.

\section{Ascription: Qualitative Before Quantitative Freedom}

A humanistic conception of management rejects the mechanistic underpinnings of neoclassical economics and is instead oriented at human freedom. This change of paradigm is optional, of course. The logic of freedom cannot be forced on people. Liberty is nothing that can be 'proven' apart from depicting how people experience it. On the methodological level, humanistic management theory therefore shifts from $3 \mathrm{rd}^{-}$person descriptions to 1 st-person ascriptions, tracking the very attributes and values which people ascribe to themselves. This methodological shift entails an epistemological one. Whereas schematic universalism is a constitutive element of each and all physical sciences, the role of universals in the humanities 
is disputed. The idea of freedom, especially, is one such contested universal. Not all who individually embrace the perspective of liberty wish to defend the idea of freedom universally. They point out that many people around the world explicitly reject the notion of liberty as an outward introjection, e.g. as a holdover from bygone eras of imperialism and colonialism. How then could such a notion serve as a universal in and as a foundation for the social sciences?

This skepticism seems exaggerated, however. Even when rejecting liberal practices, people employ the idea of freedom - implicitly. Individuals who subscribe to illiberal lifestyles aim to do so autonomously, after all. All ethical orientations, no less commitments to anti-liberal positions, lose their moral merit when imposed from without. Also totalitarians, for instance, fend for self-determination. Consequently, the foes of liberty have no good reason to deny to others the very autonomy they seek to exercise. In this self-recursive, self-legitimating sense, the idea of freedom sets itself apart from other norms with universalist pretensions. Freedom is a condition of the possibility of any manifestation of self and thus a transcendental constituent of human life. Regardless of people's specific self-ascriptions, the general nature of their lives - of biographies led in pursuit as well as in rejection of personal liberty - presupposes the very idea of freedom. In that sense, nothing speaks against a foundational use of freedom in social and economic theories and, by extension, in a humanistic management education.

Even so, not everyone understands the idea of freedom in the same way. But which understanding should be at the center of humanistic management? If, for example, freedom is reduced economically to certain consumer choices, other valid options may have been left out of the picture. Why should the idea of freedom be subordinated to the dictates of the market? Why would freedom only concern choices within a system and not also the choice of the system itself? Indeed, why limit freedom to the choice from given options instead of extending it also to the creation of new options? In short, in the realm of freedom, the powers of critique fast amounts to a critique of power.

Not incidentally, therefore, there has been a fierce contest over the labeling of freedom as negative versus positive, procedural versus substantial, idealistic versus materialistic, to name but a few of its forever fought over aspects. In the interest of brevity, I pass over the historical aspects of this struggle. Systematic clarity in the debate we gain, I hold, by focusing on the categories in which freedom is conceptualized. Predominant are the categories of quantity (extensive dimension) and quality (intensive dimension). Broadly speaking, quantitative freedom describes a maximizing concept which aims for the largest possible number or the greatest possible expansion of individual choices. On the contrary, the idea of qualitative freedom stresses the importance of evaluating, creating, and changing options. While quantitative freedom defines itself in terms of how much freedom can be granted, the concept of qualitative freedom explores which and whose freedoms are owed priority, before turning to any quantitative measuring of options (Dierksmeier 2016a, b).

The wide spectrum of standard conceptions of freedom can be accounted for within this framework. Generally speaking, quantitative conceptions, frequently of libertarian or neoliberal origin, have an affinity to the tradition of negative freedom theories, while qualitative conceptions have much in common with positive freedom, although the two do by no means fully converge. Their difference shows up as an all-important procedural dimension. Other than theories of positive freedom, the conception of qualitative freedom neither requires, nor permits ex cathedra proclamations which freedoms are to be prioritized, but rather calls on the respectively concerned individuals and institutions to make those distinctions for themselves (Dierksmeier and Pirson 2010).

In short, the abstract, structural idea of qualitative freedom ought at all times to be distinguished from attempts to specify and realize specific concepts (material and formal, 
substantial and procedural, positive and negative, etc.) of freedom. Freedom is only commendable as an arbiter of cross-cultural value questions, if we can reconcile these two notions: 1) that freedom as an idea can claim universal validity even though, or, rather, precisely because 2) certain concepts of freedom may mean different things in different places. Understanding the idea of freedom as structural in nature, not substantial, we see that freedom must be lived out in a healthy variety of ways. This way we can resolve the tenuous relation between unity and diversity in human norms premised on the capacity for self-determination. As I see it, a key weakness of previous theories of 'positive freedom' (e.g. by G.W.F. Hegel or T.H. Green) is their inability to establish this very distinction. Discussions of freedom in general then fast descend into quarrels about specific liberties in particular. Without demarcating the philosophical idea from its potential applications, the general stance for a qualitative notion of freedom is easily confused with a defense of particular policies (e.g. progressive liberalism versus economic (neo-)liberalism) that go along with specific concepts of freedom. Unlike theories of positive freedom, the conception of qualitative freedom helps us maintain this important distinction (Dierksmeier 2016a).

Devotees of quantitative freedom essentially believe that when it comes to freedom and its options, the best yardstick is "the more, the better". Proponents of quantitative freedom conceive of freedom as some kind of physical commodity in a bazaar of other desirable goods (Kymlicka 1989). For them, liberty is but a means to other ends. Freedom on this view is very much like money, an infinitely transferable means of exchange of which, assuming infinite desires, one can never have enough: a purveyor of other goods, solely to be esteemed according to its respective purchasing power. Once, however, quantitative pricing replaces qualitative prizing, the use value of freedom shrinks to its mere exchange value; it becomes tantamount to what it purchases (Carter 1999, 174).

The theoretical defaults of this reductionist version of freedom translate fast into practical defects. On this view, freedom is identified with independence and non-interference and a person can maximize her own range of options only by jealously fending off other human beings: The smaller, hence, the role of social considerations and co-determination in the shaping of individual liberties, the better. Calls for responsible regulation thus being perceived as but threats to the sovereignty of this sublime kingdom, one will always seek to avoid any and all limits of private choice (Macpherson 2012). Freedoms of physical movement and enforceable property rights are then prioritized over normative claims to entitlements and liberation (Narveson 1988; Rothbard 1977), and society is being arranged according to the model of a rational exchange.

Setting out from conceptualizing the interests of others as a negation (qua limitation) of one's own interests, rational maximizers will naturally grant their rights only insofar as they receive something equal in return. As with negative duties, so also with positive commitments: One supports others when and only insofar as they can be obliged to give support of an equal quantitative value; otherwise it would be rational to withhold cooperation. From the quantitative perspective, policies leading towards "liberalized" markets, a deregulated economy, and a minimal state are to be embraced insofar as they increase the number of available choices to individuals. On this view, the role of business ethics is basically to ensure compliance with society's laws, while fostering a sense of probity in management even when and where legal sanctions have no immediate force. Any and all efforts beyond those narrow confines must be defended against those whose options might be curtailed by such endeavors. On the whole, therefore, business ethics in accord with quantitative conceptions of freedom shuns transformative approaches and consigns itself to advocating the morals of sound housekeeping (Friedman and Friedman 1980). 
Quantitative freedom theories function only according to hypothetical, not categorical justifications; conditionally, not unconditionally motivated. Individuals positioned so far away in either time or space that they can neither be useful nor harmful to the quantitative liberty maximizers can thus not enter into the bargain (Sauvé 1995). Where symmetrical reciprocity cannot take place, the question cannot be answered: Why commit oneself to legal limits and/or social assistance at all? Questions of global and intergenerational justice have correspondingly been absent from most discussions of quantitative freedom (Nozick 1975). Also, the quantitative model of freedom comes at its limits when asymmetries of power exist that distort the voluntariness of the exchanging parties (Pettit 1997, 65f.).

Moreover, many criticize a solely quantitative approach to freedom as insufficiently nuanced and even, in the final analysis, illiberal. Recognizing that need can compel, critical reflections on the nature of economic freedom have become commonplace which contend that "no one may so acquire goods that others suffer severe loss of liberty as a result" (Cohen 1995, 37). To demand, however, that in its use individual freedom always ought to be respectful of the preconditions of universal freedom, is surely a meaningful qualification of the individuals' entitlement to liberty but, to be sure, also already a first step away from merely quantitative perspective. And this is as it should, argues Martha Nussbaum, for one. An undifferentiating maximization of options won't do, as some freedoms "are simply less important, (and) others may be positively bad" (Nussbaum 2011, 72-73). As an example of the former, Nussbaum cites "the freedom of motorcyclists to drive without helmets," and as an example of the latter, "the freedom to harass women in the workplace" (ibid.). Mere reliance on the number of options available to our pursuit of happiness blinds us to the dimension of freedom as a normatively motivated reflection and critique of our preferences and practices.

Indeed, freedom cannot be analyzed from a value-neutral standpoint. Any discussion about human freedom requires that we go beyond sheer quantities and "overall amounts" and incorporate qualitative aspects (Miller 1983). The simplified quantitative equation - more independence equals more freedom - lacks attention to the qualitative question whose autonomy is actually promoted by a certain absence of constraint (Christman 1991). Some social policies might limit individual options but, by applying equally to all, help us maintain the liberty of open societies as a whole (Kristjánsson 1996). In order to enjoy the fullest bounty of freedom, we need to see that certain strictures liberate (such as rules against violence and fraud), certain values emancipate (such as norms of solidarity and social assistance), and certain laws set us free (such as those settling coordination problems in online as well as offline traffic). In short, not only the number, also the nature of our options matters.

Qualitative theories of freedom hence follow the maxim "the better, the more," declaring we should foster with priority those options that appear most fundamental to us (Mills 1998). And, at times, the cause of freedom may at times even be served by reducing the total number of available options, when this is in the long-term interest of freedom for all (Young 1986). Policies in favor of ecological sustainability and in the interest of the rights of future generations are a case in point. Qualitatively oriented theories aim to strengthen options which meet certain criteria, such as human dignity, rationality, reciprocity, universalizability, autonomy, and so on. While quantitatively, the freedom to express a certain ('left' or 'right') opinion appears no different from, for example, the freedom to drive on a certain ('left' or 'right') side of the road, because of these criteria we may surely judge the former qualitatively more fundamental than the latter; and we can make this judgment without quantitatively measuring how much more important exactly it is. That is to say, where quantitative theories purport to offer cardinal measurements on a single utility scale, qualitative approaches operate more 
humbly and aim only for ordinal rankings of diverse, irreducible and thus incommensurable goods; whereas cardinal scales can be established by technocratic procedures such as algorithms, prioritizations of the latter require democratic processes of political deliberation (Dierksmeier 2016a).

This philosophical differentiation between quantitative and qualitative orientations of freedom theories accounts for important socio-political differences. While, in the broad context of a free market economy, quantitative theories of freedom have an inbuilt tendency to endorse a continual increase in the number of private options, qualitative approaches allow for far more differentiated judgments of economic affairs. They are asking such mundane questions as whether the consent of the parties had been manufactured by necessity or undue manipulation, or whether certain seemingly voluntary transactions do not in fact undermine human autonomy, or other core principles of a qualitative conception of freedom (Nussbaum 2011, 35). So, whereas quantitative theorists tend to regard the unfettered free market as a paradise of economic freedom allowing for the maximum of compatible voluntary exchanges, qualitative theorists also pay attention to the impact on everyone's capabilities that the economic policies have. Proponents of qualitative models, therefore, aspire to a free competition between different forms of freedom in the political forum of public debate and reassert the priority of politics over the economy (Sen 2009).

In a quantitative conception there can be but one expert answer to the question which path a free society must take, i.e. the one with the maximum number of countable individual options. Hence quantitative freedom opts for a one-size-fits-all model, whereas the philosophy of qualitative freedom calls for differences and emphasizes: The mere fact that the content of freedom - the general idea of qualitative freedom - must be qualitatively defined does not determine what ought to be demanded in the name of freedom (i.e. the specific concepts of freedom). Hence one can integrate a range of existing theories of freedom - negative, positive, emancipative, republican, procedural, etc. - into the qualitative matrix; it is an integrative, not an exclusive conception.

Moreover, by also taking counterfactual and normative considerations into account, the qualitative freedom model allows us to factor in the opportunity costs associated with the status quo. Depending on our worldview, we may regard certain constraints either as meaningful bonds or as intolerable impediments to our self-realization (Dahrendorf 2008). On such questions, there are no a priori answers. Instead, proceduralization is what the idea of qualitative freedom demands, i.e. democratizing the very value prioritizations that guide us. Those concerned by certain decision should be the ones concerning themselves with these decisions so that there is ideally an identity between the effecting and the affected parties.

Qualitative theories thereby go beyond the conditional reciprocity of social contract theories or game theories in embracing an unconditional moral point of view: Society is more than a minimalist contract to ensure property and basic rights; it is a compact geared towards the participation and self-realization of all. We are to establish and protect the liberty even of those, such as citizens of distant lands or future generations, from whom we can derive no direct benefits (Barry 1989, 163). Qualitative conceptions thus do not embrace the fantasy of a lonely but limitless freedom. They hold instead that individual liberty can only be realized within proper social bounds, which cater to the freedom of all (Tinder 2007). By linking individual freedom to universal freedom, qualitative approaches reframe responsibility for others as an inner manifestation of freedom rather than as an external barrier to self-realization: a potential qualitative bonum rather than an automatic quantitative minus in liberty.

Sociality, on this qualitative view, is not generated by the material contingencies of existence alone. Instead of contractarian or game-theoretical approaches that reduce all 
interpersonal ties to the logic of naked self-seeking, an economics based on a qualitative approach to freedom incorporates human needs for cultural exchange, symbolic communication, spiritual contemplation, and moral connection. It thus shows that and how individual freedom can be complemented via collective action (Dahrendorf 2008). The theory of qualitative freedom promotes, as a result, more socially circumspect options than its theoretical predecessors and highlights that bonds of self-obligation are hardly negations of the very liberties they limit as well as the quotidian awareness that liberty entails engagement and becomes realized through commitments.

What follows from these deliberations for humanistic management? With the qualitative prioritization of reciprocal and universalizable freedoms over a value-free lumping of any and all liberties into but one class of options, comes a shift in the burden of proof. No longer does it fall on those who fend on behalf of social, moral, and ecological sustainability but rather on those who misunderstand liberty as license. Whereas quantitative conceptions of freedom externalize responsibility, it is internalized by the idea of qualitative freedom. While quantitative theories view people as amoral, mechanic entities that need to be forced to be decent by laws or prodded by financial incentives, the perspective of qualitative freedom is more realistic because it is more idealistic. On this view, one does not only look at the vices but also the virtues of humanity, and this integration of ethical capacities into economics helps to see people as actors empowered rather than encumbered by their responsibilities. In short, yesterday's economics has been failing us because it could not understand moral commitments as the very compass the corporate world needs to fare safely in an ever more interdependent world.

For human beings who ascribe to themselves both freedom and responsibility, ethics is not just a cumbersome side-constraint hampering business. People prefer to make money, where possible, in responsible ways - and that, in a nutshell, is the business case for business ethics. An ethically informed hermeneutics boosts firms' heuristics of what their stakeholders want. Moral commitments help corporations to innovate their strategy up to the point where, eventually, they can 'do well by doing good'. To depart from the mechanistic paradigm of management in search of a truly humanistic management theory, i.e. one that recognizes that normative prescriptions are part and parcel of the self-ascriptions of economic actors as free and responsible beings, is therefore very much in the practical interest of business too.

\section{Prescription: Unconditional Dignity and the Conditions of Well-Being}

In the previous sections the deconstruction of a mechanistic description of human economic agency led to the construction of an alternative based on the self-ascription of freedom and responsibility. This move towards humanistic management theory brings about a reassessment of the normative dimension of economics. Whereas the mechanistic paradigm is ostensibly value-free, while being covertly oriented at a materialistic matrix, the humanistic paradigm is overtly normative. Why? In order to judge options as more or less meaningful, the idea of freedom requires values. In the philosophy of humanistic management, freedom is therefore not only recognized as the ultimate basis of economic activity (description), but its qualitative dimension (ascription) also extends to a demand for its responsible use (prescription).

This transition from description via ascription to prescription is exemplified by the development of the notion of human dignity over the ages (Dierksmeier 2015). Human dignity has for centuries been the lodestar of humanistic ethics in light of whose supreme value lesser goods were ranked according to their respective superiority or inferiority so that, eventually, all 
of them could be pursued together in an orderly fashion. All economic values are instrumental, functional, conditioned, and relative in regard to something of intrinsic, substantial, unconditional, or absolute value. People praise all things under the sun differently, but the act of appraising itself is transcendental to all value assessments. Things may rise or fall in appreciation, but the capacity to evaluate them does not fall amongst these 'things'. Objects have prices, but subjects have dignity, as they are the ones freely - albeit not arbitrarily - bestowing value. Human autonomy is thus the pivot around which this conception of dignity turns.

Thinkers from different times and backgrounds have, however, interpreted human dignity in different ways (Dierksmeier 2016b). Their contrasting understandings may easily lead into confusion or allow for too arbitrary an interpretation of the idea of human dignity to be operational in business contexts. Lest an excessively wide scope of meanings render us unable to identify certain policies as either in accord or in contrast with human dignity, we cannot skirt the question how human beings from different backgrounds can come to agree on the content of the idea of human dignity when disagreeing otherwise in their overall worldviews. Is there really an overlapping consensus on human dignity capable of bridging cultural divides?

Ancient philosophers established the idea of human dignity on a metaphysical basis. Medieval thinkers transformed their theories thereafter from a theological perspective. Eventually, modern philosophers tried to rid themselves of both the theological and metaphysical premises, in search of positions based on a critical self-analysis of human reasoning. As a consequence, the attribution of dignity changed over time; from antiquity, when only some humans were seen as dignified, via the medieval theologies that ascribed dignity to all humans as a result of their divine creation, to, ultimately, the era of modernity, which attaches dignity to the individual freedom of each (Dierksmeier 2015).

The advantage of taking freedom as the foundation for human dignity is patent: its selfstanding, independent foundation in the factuality of human autonomy. The German philosopher Immanuel Kant (1724-1804), for example, rejected the common notion that one is free first - and then, later, submits (or not) to moral laws. The crucial but at first somewhat counterintuitive point of this argumentation is to explain human freedom itself from the ability to realize moral commands, not vice versa. If the human being were only (negatively) free from natural impulses but not also (positively) free to realize a higher, i.e. the moral law, then human freedom would appear merely as an erratic deviation from an otherwise regular (i.e. naturally determined) behavior. Free actions would consequently be wholly unpredictable and we could not hold any morally responsible for them (Dierksmeier 1998). Human freedom, however, is not a chaotic deviation from the determining agency of natural causes. Rather, Kant holds, the call of the moral law liberates us from natural inclination by making us free to steer a course toward moral ends. Through our ability to be moral, we gain freedom - both to be moral, and also, derivatively, to be immoral (Timmermann 2008).

Not arbitrary choice ("quantitative freedom") but our capacity for moral autonomy ("qualitative freedom") must be seen as the true source of the unique status of the human being and its dignity. Even so, says Kant, it is not factual moral obedience to the moral command that (conditionally) accounts for our dignity but rather the (unconditional) ability to this very obedience, even when it does not materialize into moral actions. Every human being has dignity (Würde) - through being able to be moral - but only those who do, in fact, lead moral lives also deserve the praise of personal ethical value (Wert). This distinction enables us to reconcile the otherwise conflicting intuitions that, while we must respect the dignity of each, we should reserve qualified praise for those leading lives beyond reproach (Dierksmeier 1998). We need to respect and protect the dignity of human life even in those who, in our eyes, 
constantly make bad choices. Respect for dignity means to protect the capacity of the human being to define its own ends, ideally but not always actually, in pursuit of a moral life.

With Kant we thus enter a phase of theorizing, where the values and virtues of business ethics are derived from the inward autonomy of the concerned subjects rather than from outward metaphysical premises. When so based on autonomy, the principle of human dignity acquires a transcultural meaning able to bridge civilizational divides: different cultures can each elevate divergent lifestyles as moral, while all agreeing that so to disagree does not mean to differ on everything. Rather, they can at the same time agree on the foundational role of autonomy, i.e. on the entitlement of each and all human beings to reasonable self-determination. In today's multicultural world, it appears wise, therefore, to treat dignity-based-onautonomy not merely as one value amongst many but as the overarching principle in light of which management should be taught and practiced.

As we derived the principle of human dignity based on the idea of qualitative freedom, we immediately see that respect for human dignity entails not only negative but also positive obligations, and that it reaches beyond the field of human rights into the realm of human responsibilities. To declare for the unconditional dignity of human life entails, therefore, also a concern for the conditions under which such dignity flourishes. The humanistic focus on dignity goes, consequently, hand in hand with the fostering of humane life conditions. Humanistic management goes thus beyond respecting and protecting the dignity of all - a position we could also arrive at starting off a position of quantitative liberty. In the tradition of qualitative freedom, it comprises also a demand to promote the capabilities of each so that any and all human beings can freely achieve a life they have reason to value (Sen 2002). While defending the unconditional ascription of dignity to all humans indiscriminately, this approach recognizes also that all individuals realize their dignity in their own special way, i.e. in and according to their own freedom. There is, therefore, no 'one-size-fits-all' way for promoting the capabilities on which human dignity thrives.

\section{Challenges: Deep Ecology and the Age of Postmodernity}

The humanistic management approach may seem outdated to some. The very premises of the humanistic approach have long since been questioned. Being disinclined to follow 'master narratives' and 'false universals' has provoked a postmodern skepticism against a normative use of the concept of humanism. This theoretical doubt is met by practical objections voiced by adherents of the 'deep ecology' movement who feel it is high time for humanity to step down from its pedestal and acknowledge, respect, and protect the non-human life forms (Melé 2009, 124-125).

Both arguments have much in their favor. In the last centuries conceptions of one 'human essence' and its nature have indeed been misused in order to suppress difference and diversity in the interest of intolerable normative constructs (colonialist paternalism, white supremacy, etc.). Likewise, vaulted conceptions of the uniqueness of humanity were instrumentalized to justify the exploitation of nature and suppression of other life forms. As a consequence, numerous thinkers advise we had from now on better stay clear off all anthropocentrism and rather seek out post-humanistic ideologies (Welsch 1988).

One can, however, share those concerns without taking refuge to the solutions advocated for by these critics. Humanistic management does neither necessarily lead one to an anthropocentric disregard for the non-human biosphere, nor does it force upon its adherents a 
monolithic ethics lethal to any and all cultural difference. The first point can be made rather briefly. The second shall need a more detailed elaboration.

First, humanism need not be anthropocentric. The humanistic position, rightly understood, transcends the anthropocentrism/biocentrism divide: Even biocentrists, i.e. also adherents of 'deep ecology', have to make 'tough decisions' when the vivid interests of certain life forms conflict. When making any 'trade-off' (e.g. by hindering - or not - certain predators killing their prey), biocentrists are de facto taking a stance on which interests deserve priority. If these decisions are not to be arbitrary, they will follow ethical rationales, which in turn must express a hierarchy of criteria which aim to assess the intrinsic value of the conflicting life forms fairly.

As far as we know, on planet earth only human beings are making such decisions in reference to reasons open to the scrutiny and criticism of others. As a consequence, the demands of biocentrist theory can only be realized in practice through an assessment of the inherent value of life forms. This assessment, however, cannot be made but in relation to what we, as humans, have thus far come to know about life. This does not imply that those judgments have to be self-serving. On the contrary, it is the interest of every fair-minded ethicist to reduce any species-bound bias as far as possible. Instead of putting the human species above others, a critical approach to humanism might rather imply to infer from our specific capacities and capabilities a particular responsibility for all life on earth. We would thus more adequately call the humanist angle 'anthroporelational' than 'anthropocentric.'

While the concerns of the 'deep ecology' movement can rather easily be accommodated, the postmodern resistance against each and all universalist positions poses a stronger challenge to the conception of humanistic management. How indeed can one, in the face of the patent diversity of human customs and cultures, make an inter-personally and inter-culturally valid use of ethical ideas such as the idea of unconditional human dignity? Admittedly, vis-à-vis the multi-cultural premises of social life in the present age of globality, only theories capable of meeting postmodern and relativistic challenges can convince. But is not the humanists' insistence on the primacy of dignity, embedded as it is in Western philosophical and theological traditions, precisely for that reason a hopelessly regionalist approach? To some, the predominance of Western cultural traditions in the development of the notion of dignity discredits from the outset any effort of establishing globally acceptable norms based on it. How, the argument goes, can regional values justify universal postulates? Why should the philosophy of the West dominate the rest? Do we not thus betray in procedure what we affirm in substance, i.e. a truly global approach to ethics?

Whereas, indeed, the debate over human dignity is strongly influenced by Western sources, notions of human dignity were and still are operative also in African and Asian philosophies and religions (Kresse 2011; Kirloskar-Steinbach 2011). But even if this was not the case, we must not conflate the 'genesis' and the 'validity' of philosophical arguments. All concepts at first originate within given cultures, and this per se does not impede their universal validity. Rather, in appealing to human reason, philosophical positions from everywhere in the world aim for interpersonal plausibility across all cultural boundaries. In intent, at least, also concepts coined in the West are not Western but cosmopolitan - and can thus be critically measured against their global claims.

One can reject, of course, the idea that there is but one human reason operative in all human beings, to be accessed from everywhere on earth. Yet this rejection itself makes a claim for its respective description of the nature of (a now culturally or geographically fractured) human reason. The ensuing debate which conception of rationality - pro or contra the unity of human reason - merits our eventual approval then again takes place before the court of reason (Welsch 
2002). And there, either party may fail to corroborate its claims with convincing arguments, which, however, can only be assessed after a critical examination of the respective theory at hand, i.e. after taking recourse to the self-critical potentials of human rationality. In short, there is no way to resolve the debate on the cultural relativity of rational standards other than through the employment of the very capacities of critical human reasoning, whose universal character the relativists so staunchly deny.

Ethical relativists, to avoid self-contradiction, can uphold their position only by refraining from claiming interpersonal validity for it - which some, in the interest of consistency, also do. Their arguments, however, then carry no longer the potential to legitimate but only to explain their position. Hence nothing compels anyone else to follow the relativistic train of their thoughts rather than, say, rationality conceptions of a more comprehensive scope. By insulating against the winds of criticism, the relativists isolate their arguments from the very oxygen they need to spark intellectual fires elsewhere.

Moreover, since only some - neither all, nor most - non-Western philosophers reject universal principles, ethical relativism does injustice to those thinkers, who explicitly wish to be part of the cosmopolitan project. Philosophers like Amartya Sen demand that thinkers from non-Western countries be taken seriously when they argue against certain (restrictive) values of their own region and in favor of (more emancipating) global principles (Sen 2000; Sen 2005). Their dissenting voices can be seen as a de facto contradiction to the assumption that different contexts necessarily breed diverging views. Cultural stereotypes must, that is to say, not let us overlook extraterritorial advocates of the idea of human dignity. Worse than the imperialistic imposition of rights to protect human dignity is, surely, a relativistic acquiescence in their oppression.

Since Western philosophy forever aimed to speak to all human beings, and did so in a continuous discourse reaching from Plato until today, we should focus less on the geographical realm of its origins and more on the broad scope of its ideas. The answers of Western philosophers to questions about the nature and meaning of human freedom, responsibility, and dignity need, of course, not uncritically be worshiped as ultimate capstones of human wisdom. Yet they are important stepping-stones for a global debate about the values of human life within a proceduralist conception of the humanist project.

So understood, the approach of humanistic management is fully in line with attempts on part of the world community to formulate a shared understanding of the essential ethical commitments of humanity. Not only did the UN issue in 1948 the Universal Declaration of Human Rights, anchored, according to its preamble, in the "recognition of the inherent dignity" of each and every human being. Also, in 1976, it went beyond this legally not binding declaration, and enclosed most of its tenets in the International Covenant on Civil and Political Rights, which does constitute legal obligations for all signatories. In this latter covenant, the international community again is expressly "recognizing that these rights derive from the inherent dignity of the human person."

Together, these declarations make explicit the implicit assumption that indeed there is a sufficient consensus about the nature of human dignity, underlying otherwise diverging cultural and religious backgrounds, so as to tackle the global problems of humanity. They, in short, depart from a moral consensus of humanity that does not smack of ethical imperialism. As ample research by the Global Ethic Project, launched, several decades ago, by Hans Küng at the University of Tübingen, has shown, the central values affirmed in these documents overlap with a set of norms that can be derived from all spiritual and secular traditions of humanity as a truly "global ethic" (Hans Küng 1990). According to Hans Küng, humanity's 
ethical norms converge in two basic principles and four directives shared by peoples of all cultural and religious traditions: (1) the Golden Rule of Reciprocity ('Do unto others what you would have others do unto you'); (2) the Principle of Humanity (that every human being must be treated humanely, not inhumanely); (3) non-violence and respect for life; (4) solidarity and a just economic order; (5) tolerance and truthfulness and (6) equal rights or partnership between men and women (Küng 1990; Küng et al. 2012). Despite the cultural and religious diversity in the world and the historically developed particularisms of each tradition, these basic ethical elements have surfaced time and again. One can find the tenets of a global ethic expressed in the analects of Confucius, written five centuries before Christ, in the teachings of Patañjali, the compiler of the Yoga Sutras in the Buddhist canon, as well as in the scriptures of the three monotheistic traditions: the Hebrew Bible, the New Testament, and the Koran.

While it is important to note that particular cultural determinants and historical constellations (such as a specific place or time) have favored different prioritizations and implementations (or conscious suppression), history has indeed proven that people of all walks of life can and have agreed upon these essential ethical elements. The notion of a global ethic is thus, in fact, a transcultural 'universal' of humanity. Through such a 'humanistic consensus' (Dierksmeier 2011) in regard to human values and virtues the extremes of moral relativism on the one hand and an arbitrary dogmatization of certain norms on the other might indeed be avoided.

As I understand it, the 'Global Ethic Project' neither aims to replace nor even to articulate the ethics of everyday life in particular. It is intent, instead, on highlighting their convergent elements so as to enable cross-cultural dialogue over contested ethical issues. Thus the notion of a 'Global Ethic' does not end, but open the discourse on our cosmopolitan responsibilities; it

points to implicit convergence that enables humanity to cope with the explicit divergence of conflicting interests and contrary norms. While the outcome of these global conversations on how to address the shared problems of humanity cannot be anticipated, adherence to the aforementioned principles ought to assure that the outcomes will be acceptable to all discussants. To such transcultural conversations, everyone can and should contribute, because the humanistic perspective is never partisan to anyone creed or metaphysical conviction but welcomes all secular and spiritual efforts at promotion human dignity.

Some religions offer highly interesting accounts of how to do business ethically, others contain helpful mental models, which capture the humanistic ethos of an unconditional respect for human dignity and give apt expression to the cosmopolitan responsibility of humanity. Yet the concept of humanistic management is not dependent on anyone faith or religious conviction, since, importantly, also from agnostic and atheist premises the essential tenets of humanistic management can also be endorsed and embraced (Dierksmeier 2016a, b).

\section{Conclusions: Postulates for Practice}

Rethinking economic transactions fundamentally as human relations, we arrive at the postulate that business must throughout serve the goals of humanity, not vice versa. From the perspective of humanistic management, humans need to be reinstated throughout the economic system as active subjects and must neither in theory, nor in practice be treated merely as passive objects, e.g. solely as cost factors or labor suppliers, i.e., as secondary factors in an economy geared to primarily other goals. Humanistic management scholarship endorses and affirms, therefore, the centrality of human rights for all forms and aspects of management (Ulrich 2008; Leisinger 2009). 
The operationalization of humanistic management in the various sectors of business touches on technical questions of implementation and business model development as well as on aspects of strategy innovation that lie outside the scope of this article. There is, however, already an intensive discussion going on in the ambit of humanistic management scholarship; in the 'Humanism in Business' book series at Palgrave/Macmillan where at this point of writing there have already been published 13 volumes on a wide variety of subjects, such as marketing (Varey and Pirson 2014), international business and management (Lupton and Pirson 2014). Case studies on firms with humanistic management strategies both in the real economy (von Kimakowitz et al. 2011) and in the financial economy (Spitzeck et al. 2012), as well as studies on leadership (Lepeley et al. 2016), up to more theoretical questions as to possible transformations of capitalism (Pirson et al. 2014) and the possibilities of intercultural ethics (Dierksmeier et al. 2011) or a 'world humanism' (Khan and Amann 2013). In their own way, these volumes contain multiple 'proofs of concept' of the feasibility of humanistic management in practice and corroborate that humanistic principles can be embedded in different and various contexts of business arena, anywhere on the globe.

While the specifics of humanistic management practices are subject to further research and debate, one can draw out some conceptual lines that connect the idea of qualitative freedom and the principle of human dignity in such a way as to provide some general normative guidance. As we saw, quantitative liberty is oriented around an atomistic subject that aims to keep its fellow beings at bay, while the idea of qualitative freedom operates from a relational concept of personality; so, where the former seeks freedom through independence, the latter finds it in social interdependence (Dierksmeier and Pirson 2010). Likewise, while quantitative freedom affords the natural, cultural, social, and political foundations of individual freedom, by definition, at best a secondary status, they are of primary importance to the idea of qualitative freedom as its defines its concrete manifestations in reference to its contexts (Dierksmeier 2016a, b).

Until recently, the haute couture of business ethics was modeled for the narrow catwalk of a strictly quantitative as well as materialistic conception of incentives. The academic guild fashioned tight corsets of 'compliance management', constricting the gait of their wearers to extremely contracted conceptions of 'corporate social responsibility'. No wonder, then, that managers and employees, principals as well as agents, forever tried to rid themselves of these homo economicus straitjackets. Which is why now, finally, the tailors of business ethics ponder whether not more loosely woven threads might make for a more flexible fabric, better apt for novel patterns and qualitative criteria (Dierksmeier and Pirson 2010).

Since the idea of qualitative freedom is premised on relational concept of autonomy, it turns against shareholder theory and its postulate of but a single objective function (Jensen 2002; Sundaram and Inkpen 2004). In contrast to theories of quantitative freedom which assume the world to be peopled by purely opportunistic maximizers, the qualitative notion views people as optimizers who manifest their personal freedom in accord with their social relations (Dierksmeier and Pirson 2010). Whereas quantitative freedom aligns with principal/agenttheory and with transaction management doctrines, from the perspective of qualitative freedom one would rather endorse the anthropology of stewardship theory (Davis et al. 1997; Donaldson and Davis 1991) and transformational (e.g. Bass and Avolio 1994; Burns 1978) leadership styles. Also a close fit with the theory of qualitative freedom are self-management oriented leadership styles (Manz and Sims 1993; Politis 2001), as these theories do not make a strict distinction between leaders and followers but rather advocate for the responsibility of all and the dominance of no-one. 
Quantitative freedom theories endorse transactional cultures (Bass and Avolio 1994) and corporate identities that are oriented strictly toward the individual (Brickson 2005). Qualitative notions of freedom support transformational corporate cultures which are more communally oriented (Brickson 2007). Since from the humanistic perspective, companies are not mere sets of contracts for profit generation, but, quite literally, in-corporations of individuals, they ought to be re-designed into vehicles for the cultivation of human relationships inside and outside the firm's legal boundaries. As a consequence, businesses ought to avoid control mechanisms obstructing creativity and initiative but rather encourage spontaneous exchanges with and between their stakeholders. In this sense, the importance of democratic dialogue-based processes and participatory management has been strongly affirmed by humanistic management scholars (Amann and Khan 2011; Largacha-Martinez 2011).

These postulates reflect the perspective of human dignity. Humanistic management, after all, ultimately aims at the recognition, defense, and promotion of human dignity as preceding any other considerations and as an end of business in and for itself (Amann and StachowiczStanusch 2013). While there are conditional rationales for humanistic business practices insofar as these may boost employee morale and productivity as well as customer loyalty and stakeholder goodwill, they are always in peril of being abolished as soon as their respective preconditions fail to materialize. The litmus test of humanistic management is thus an unconditional commitment to orient business at the intrinsic worth of human life, that is, a reconceptualization of business as being at the service of human dignity and the flourishing of human life (Melé and Dierksmeier 2012).

The attempt of giving a comprehensive account of what kind of values should be given priority in whichever situation and socio-cultural environment would, however, fly in the face of the liberal commitment of the humanistic management conception. Taking seriously that human dignity is premised on moral autonomy the approach of humanistic management to specifying the demands for the promotion of dignity at the workplace is procedural and participatory: Humanistic management, to repeat, aims to honor the freedom of each business stakeholder by involving them, as much as possible, into the making of those decisions that impact their lives. Ideally, everyone should be able to have an effect on management who is affected by it, wherever possible directly, and where impossible indirectly by way of representation.

Nonetheless, with a view to the inter-culturally acceptable global ethical standards, and concentrated on both the unconditional as well as the conditional aspect of dignity, certain contours of management can be delineated which circumscribe essential tenets of any management with humanistic ambitions and intentions. Thus certain substantial demands flow from the procedural commitment of the principle of humanistic management. While firms cannot and must not dictate a certain ethos for their employees, they ought to back their employees in practicing their own moral commitments insofar as these do not militate against the ethical efforts of others. Companies thus do well to support the self-perfecting activities of their employees directly - where there is consensus on the ethical direction and, at any rate, indirectly through enhancing their employees' human capabilities. While oftentimes the impression is generated that the diversity of human civilizations and cultures presents an insurmountable obstacle to conjoint ethical efforts in the age of globality, in fact there appears to be a sizable 'humanistic consensus' (Dierksmeier 2011) around some core values such as those outlined by the 'Global Ethic Project,' which can very well serve as a normative focal point for management practice as well as management theory and business education. 


\section{Summary: Humanistic Management as a Procedure and a Project}

In the age of globality, everyone's economic interests are increasingly enmeshed with those of everyone else. Both within the firm and in relation to its various stakeholders a need for global ethical standards is ever more strongly felt. Global economies require a cosmopolitan ethic directed by a joint humanistic vision that can be endorsed by values and norms substantiated by the common human experience. Yet both in theory and in practice, management is today far from meeting this need for a cosmopolitan ethos.

Neglect of the idea of freedom in economics has led to an inadequate conceptualization of ethical responsibilities within management theory. In a critical review of the history of economic ideas, I have investigated how the idea of freedom was gradually removed from the canon of economics. This reconstruction led to a deconstruction of certain axioms of neoclassical economics that hamper contemporary efforts in integrating ethics firmly into management education. This goes to show that a constructive use of the idea of responsible freedom could correct and complement the current quantitative focus in business theory through qualitative orientations.

At the root of the humanistic conception of business lies the insight that a functioning economy is not driven by impersonal, blind economic forces but rather rests on the personal freedom of each and depends on the responsibility of all. Business is, after all, conducted by people, with people, for people (Dierksmeier 2011). Since not only materialistic tendencies but also idealistic aspirations define human life, values and virtues should also become an essential component of management theory. Since moral motifs, just as much as material motivations are drivers of human behavior, economic anthropology would be myopic were it not also informed by the ethics aspirations of humanity.

Yet any and all forms of moral responsibility presuppose individual freedom, which is why humanistic management theory cannot be advanced without a viable conception of freedom. Turning away from the overly reductionist, quantitative notions of economic liberty that have been popularized by the Chicago School of Economics, I suggested to embrace instead a qualitative idea of responsible freedom. Guided by this idea we might orient business conduct away from a focus on quantitative maximization to richer qualitative standards directed by a by human dignity at their center.

Humanistic management is a conception encompassing moral, social, and ecological sustainability criteria precisely because it sees individual autonomy not just as an entitlement for self-determination but also as an obligation for self-commitment: Individual liberty and cosmopolitan responsibility belong together and strengthen one another. Yet given the multicultural setup of contemporary business and the plurality of normative views espoused all over the world, the integration of ethical considerations into management theory must be accomplished in ways that respect the legitimate differences of cultures and civilizations. Respect for difference does, however, not rule out the identification and operationalization of norms on which humanity converges. A 'global ethic,' built around principles and values which people from everywhere have forever agreed on, can be an important lodestar for the increasingly cosmopolitan tasks of humanistic management. In light of these perspectives, humanistic management not only stands up for the human rights of each but also reminds us of the human responsibilities of us all. Humanistic management, in short, aspires to use business as a means for the end of improving each and every individual's conditions in the interest and service of their unconditional dignity. 
Acknowledgments For assistance and instructive feedback I wish to thank Michael Pirson, Laura Dierksmeier, and Gustav Theile.

\section{References}

Amann, Wolfgang, and Shiban Khan. 2011. Dialogue-based leadership style as part of humanistic organizational cultures: The case of Dm in Germany. In Humanistic management in practice. Humanism in Business Series, ed. Ernst von Kimakowitz, Michael Pirson, Heiko Spitzeck, Claus Dierksmeier, and Wolfgang Amann, 92-102. New York: Palgrave Macmillan.

Amann, Wolfgang, and Agata Stachowicz-Stanusch (eds.). 2013. Integrity in organizations: Building the foundations for humanistic management. Humanism in business series. New York: Palgrave Macmillan.

Backhaus, Jürgen. 2000. Methodenstreit in der Nationalökonomie. Journal for General Philosophy of Science 31(2): 307-336.

Barry, Brian. 1989. Theories of justice. California Series on Social Choice and Political Economy 16. Berkeley: University of California Press.

Bass, Bernard M., and Bruce J. Avolio. 1994. Transformational leadership and organizational culture. International Journal of Public Administration 17(3-4): 541-554.

Bostaph, Samuel. 1978. The methodological debate between Carl Menger and the German historicists. Atlantic Economic Journal 6(3): 3-16.

Boudling, Kenneth E. 1969. Economics as a moral science. The American Economic Review 59(1): 1-12.

Brickson, Shelley L. 2005. Organizational identity orientation: Forging a link between organizational identity and organizations' relations with stakeholders. Administrative Science Quarterly 50(4): 576-609.

Brickson, Shelley L. 2007. Organizational identity orientation: The genesis of the role of the firm and distinct forms of social value. Academy of Management Review 32(3): 864-888.

Brodbeck, Karl-Heinz. 2013. Die fragwürdigen Grundlagen der Ökonomie: Eine philosophische Kritik der modernen Wirtschaftswissenschaften. 6., um ein aktuelles Vorw. erw. Aufl. Darmstadt: WBG Wiss. Buchges.

Burns, James M. 1978. Leadership. New York: Harper \& Row.

Carter, Ian. 1999. A measure of freedom. 1. publ. Oxford: Oxford Univ. Press.

Christman, John. 1991. Liberalism and individual positive freedom. Ethics 101(2): 343-359.

Cohen, Gerald A. 1995. Self-Ownership, Freedom, and Equality. Studies in Marxism and social theory. Cambridge, New York, Paris: Cambridge University Press, Maison des sciences de l'homme.

Colander, David. 2000. The death of neoclassical economics. Journal of the History of Economic Thought 22(02): 127-143.

Colander, David, Richard Holt, and Barkley Rosser. 2004. The changing face of mainstream economics. Review of Political Economy 16(4): 485-499.

Dahrendorf, Ralf. 2008. The modern social conflict: The politics of liberty. Completely rev. 2nd ed. New Brunswick, N.J. Transaction Publishers.

Davis, J.H., F.D. Schoorman, and L. Donaldson. 1997. Toward a stewardship theory of management. Academy of Management Review 22(1): 20-47.

Dequech, David. 2007. Neoclassical, mainstream, orthodox, and heterodox economics. Journal of Post Keynesian Economics 30(2): 279-302.

Dierksmeier, Claus. 1998. Das Noumenon Religion: Eine Untersuchung zur Stellung der Religion im System der praktischen Philosophie Kants. Kantstudien Ergänzungshefte 133. Berlin, New York: De Gruyter.

Dierksmeier, Claus. 2011. The freedom-responsibility nexus in management philosophy and business ethics. Journal of Business Ethics 101(2): 263-283.

Dierksmeier, Claus. 2015. Human dignity and the business of business. Human Systems Management 34(2015): $33-42$.

Dierksmeier, Claus. 2016a. Qualitative Freiheit: Selbstbestimmung in weltbürgerlicher Verantwortung. Bielefeld: transcript.

Dierksmeier, Claus. 2016. Reframing economic ethics: The philosophical foundations of humanistic management. Humanism in business series. New York: Palgrave Macmillan.

Dierksmeier, Claus, and Anthony Celano. 2012. Thomas Aquinas on justice as a global virtue in business. Business Ethics Quarterly 22(2): 247-272.

Dierksmeier, Claus, and Michael Pirson. 2010. The modern corporation and the idea of freedom. Philosophy of Management 9(3): 5-25. 
Dierksmeier, Claus, Wolfgang Amann, Ernst von Kimakowitz, Heiko Spitzeck, and Michael Pirson (eds.) 2011. Humanistic ethics in the age of globality. Humanism in business series. New York: Palgrave Macmillan.

diZerega, Gus. 1997. Market non-neutrality: Systemic bias in spontaneous orders. Critical Review 11(1): 121144.

Donaldson, L., and J.H. Davis. 1991. Stewardship theory or agency theory: CEO governance and shareholder returns. Australian Journal of Management 16(1): 49-64.

Douglas, Heather E. 2009. Science, policy, and the value-free ideal. Pittsburgh: University of Pittsburgh Press.

Fournier, V., and C. Grey. 2000. At the critical moment: Conditions and prospects for critical management studies. Human Relations 53(1): 7-32.

Freeman, R.E., Andrew C. Wicks, and Bidhan Parmar. 2004. Stakeholder theory and "The Corporate Objective Revisited". Organization Science 15(3): 364-369.

Freeman, R.E., Kirsten Martin, and Bidhan Parmar. 2007. Stakeholder capitalism. Journal of Business Ethics 74(4): 303-314.

Friedman, Milton. 1953. Essays in positive economics. Chicago: Univ. of Chicago Press.

Friedman, Milton, and Rose D. Friedman. 1980. Free to choose: A personal statement, 1st ed. New York: Harcourt Brace Jovanovich.

Friedman, Milton. 1970. "The Social Responsibility of Business is to Increase its Profits.” The New York Times Magazine.

Galbraith, John K. 1967/1986. The New Industrial State. Boston: Houghton Mifflin.

Ghoshal, S. 2005. Bad management theories are destroying good management practices. Academy of Management Learning \& Education 4(1): 75-91.

Gladwin, Thomas N., James J. Kennelly, and Tara-Shelomith Krause. 1995. Shifting paradigms for sustainable development: Implications for mangement theory and research. The Academy Management Review 20(4): $874-907$.

Hart, Stuart L. 2005. Capitalism at the Crossroads: The Unlimited Business Opportunities in Solving the World's Most Difficult Problems. 1. print. Philadelphia, Pa. Wharton School Publ.

Hayek, Friedrich A. 1952. The counter-revolution of science. Glencoe: Free Press.

Hühn, Matthias P., and Claus Dierksmeier. 2014. "Will the Real A. Smith Please Stand Up!”. Journal of Business Ethics, 1-14.

Jensen, Michael C. 2002. Value maximization, stakeholder theory, and the corporate objective function. Business Ethics Quarterly 12(2): 235-256.

Jevons, William S. 1871. "The Power of Numerical Discrimination."

Khan, Shiban, and Wolfgang Amann (eds.). 2013. World humanism. Humanism in business series. New York: Palgrave Macmillan.

Kirloskar-Steinbach, Monika. 2011. Humanistic values in Indian and Chinese traditions. In Humanistic ethics in the age of globality. Humanism in business series, ed. Claus Dierksmeier, Wolfgang Amann, Ernst von Kimakowitz, Heiko Spitzeck, and Michael Pirson, 225-245. New York: Palgrave Macmillan.

Kresse, Kai. 2011. "African Humanism" and a case study from the Swahili coast. In Humanistic ethics in the age of globality. Humanism in business series, ed. Claus Dierksmeier, Wolfgang Amann, Ernst von Kimakowitz, Heiko Spitzeck, and Michael Pirson, 246-265. New York: Palgrave Macmillan.

Kristjánsson, Kristján. 1996. Social freedom: The responsibility view. Cambridge England, New York: Cambridge University Press.

Küng, Hans. 1990. Projekt Weltethos. München: Piper.

Küng, Hans, Günther Gebhardt, and Stephan Schlensog. 2012. Handbuch Weltethos: Eine Vision und ihre Umsetzung. Orig.-Ausg. Piper 30059. München: Piper.

Kymlicka, Will. 1989. Liberal individualism and liberal neutrality. Ethics 99(4): 883-905.

Largacha-Martinez, Carlos. 2011. What is your calling? SEMCO's invitation to participatory management. In Humanistic management in practice. Humanism in Business Series, ed. Ernst von Kimakowitz, Michael Pirson, Heiko Spitzeck, Claus Dierksmeier, and Wolfgang Amann, 215-230. New York: Palgrave Macmillan.

Leisinger, Klaus. 2009. On corporate responsibility for human rights. In Humanism in business, ed. Heiko Spitzeck, Michael Pirson, Wolfgang Amann, Shiban Khan, and Ernst von Kimakowitz, 175-203. Cambridge: Cambridge Univ. Press.

Lepeley, María-Teresa, Ernst von Kimakowitz, and Roland Bardy (eds.). 2016. Human centered management in executive education: Global imperatives, innovation and new directions. Humanism in business series. New York: Palgrave Macmillan.

Lucas, Robert E. 1988. On the mechanics of economic development. Journal of Monetary Economics 22(1): 3-42.

Lupton, Nathaniel, and Michael Pirson (eds.). 2014. Humanistic perspectives on international business and management. Humanism in business series. New York: Palgrave Macmillan.

Macpherson, Crawford B. 2012. Democratic theory: Essays in retrieval. Wynford project. Don Mills: Oxford Univ. Press. 
Manz, Charles C., and Henry P. Sims Jr. 1993. Business without bosses. New York: Wiley.

Marshall, Alfred. 1890/1920. Principles of Economics. 8th ed. London: Macmillan.

McCloskey, Deirdre N. 1994. Knowledge and persuasion in Economics. Cambridge: Cambridge Univ. Press.

Mearman, Andrew. 2011. Who do heterodox economists think they are? American Journal of Economics and Sociology 70(2): 480-510.

Melé, Domènec. 2009. Current trends in humanism and business. In Humanism in business, ed. Heiko Spitzeck, Michael Pirson, Wolfgang Amann, Shiban Khan, and Ernst von Kimakowitz, 123-140. Cambridge: Cambridge Univ. Press.

Melé, Domènec, and Claus Dierksmeier. 2012. Human development in business: Values and humanistic management in the encyclical Caritas in veritate. Humanism in business series. New York: Palgrave Macmillan.

Menger, Carl. 1871. Grundsätze der Volkswirtschaftslehre: Erster Allgemeiner Theil. Wien: Wilhelm Braumüller.

Menger, Carl. 1883. Untersuchungen über die Methode der Sozialwissenschaft und der Politischen Ökonomie insbesondere. Leipzig: Duncker und Humblot.

Miller, David. 1983. Constraints on freedom. Ethics 94(1): 66-86.

Mills, Claudia. 1998. Choice and circumstance*. Ethics 109(1): 154-165.

Narveson, Jan. 1988. The libertarian idea. Ethics and action. Philadelphia: Temple Univ. Pr.

Nguyen Huy, Quy. 2000. Do humanistic values matter? Academy of Management Proceedings 2000(1): A1-A6.

Nozick, Robert. 1975. Anarchy, state, and utopia. Oxford: Blackwell.

Nussbaum, Martha C. 2011. Creating capabilities: The human development approach. Cambridge: Belknap Press of Harvard Univ. Press.

Parker, Martin. 2002. Against management: Organization in the age of managerialism. Cambridge: Polity.

Pettit, Philip. 1997. Republicanism: A theory of freedom and government. Oxford political theory. Oxford: Oxford University Press.

Pigou, Arthur C. 1962. The economics of welfare. London: Macmillan.

Pirson, Michael A., and Paul R. Lawrence. 2010. Humanism in business - towards a paradigm shift? Journal of Business Ethics 93(4): 553-565.

Pirson, Michael, Ulrich Steinvorth, Carlos Largacha-Martinez, Claus Dierksmeier, and J.R. Mulryne (eds.). 2014. From capitalistic to humanistic business. Humanism in business series. New York: Palgrave Macmillan.

Politis, John D. 2001. The relationship of various leadership styles to knowledge management. Leadership \& Organization Development Journal 22(8): 354-364.

Robbins, Lionel. 1932. An essay on the nature and significance of economic science. New York: New York University Press.

Rothbard, Murray N. 1977. Power and market: Government and the economy. The studies in economic theory series, 2nd ed. Kansas City: Andrews and McMeel.

Rudner, Richard. 1953. The scientist qua scientist makes value judgments. Philosophy of Science 20(1): 1-6.

Samuelson, Paul. 1947/1983. Foundations of Economic Analysis. enlarged ed. Boston: Harvard University Press.

Sauvé, Kevin. 1995. Gauthier, property rights, and future generations. Canadian Journal of PHilosophy 25(2): $163-176$.

Schmoller, Gustav v. 1883. Zur Methodologie der Staats- und Sozialwissenschaften. Schmollers Jahrbuch für Gesetzgebung, Verwaltung und Volkswirtschaft 7: 976-977.

Schmoller, Gustav v. 1893/1949. Die Volkswirtschaft, die Volkswirtschaftslehre und ihre Methode. reprinted. Frankfurt.

Schumpeter, Joseph A. 1954. History of economic analysis. New York: Oxford University Press.

Sen, Amartya K. 2000. Development as freedom, 1 Anchor Booksth ed. New York: Anchor Books.

Sen, Amartya. 2002. Rationality and freedom. Cambridge: Belknap Press.

Sen, Amartya. 2005. The argumentative Indian: Writings on indian history, culture, and identity, 1 Americanth ed. New York: Farrar Straus and Giroux.

Sen, Amartya. 2009. "Capitalism Beyond the Crisis." New York Review of Books 56(5).

Spiegel, Henry W. 1971. The growth of economic thought. Durham: Duke University Press.

Spitzeck, Heiko, Michael Pirson, Wolfgang Amann, Shiban Khan, and Ernst von Kimakowitz (eds.). 2009. Humanism in business. Cambridge: Cambridge Univ. Press.

Spitzeck, Heiko, Michael Pirson, and Claus Dierksmeier (eds.). 2012. Banking with integrity: The winners of the financial crisis? New York: Palgrave Macmillan.

Stigler, George, and Gary Becker. 1977. De Gustibus Non Est Disputandum. American Economic Review 67(2): 76-90.

Streeck, Wolfgang. 2013. Gekaufte Zeit: Die vertagte Krise des demokratischen Kapitalismus; Frankfurter Adorno-Vorlesungen 2012, 1st ed. Berlin: Suhrkamp.

Sundaram, Anant K., and Andrew C. Inkpen. 2004. The corporate objective revisited. Organisation Science 15(3): 350-363. 
Timmermann, Jens. 2008. Limiting freedom: On the free choice of ends in Kantian Moral Philosophy. In Recht und Frieden in der Philosophie Kants: Akten des X. Internationalen Kant-Kongresses, vol. 3, ed. V. Rohden, R.R. Terra, G.A. de Almeida, and M. Ruffing, 427-437.

Tinder, Glenn E. 2007. Liberty: Rethinking an imperiled ideal. Emory University studies in law and religion. Grand Rapids: William B. Eerdmans Pub.

Ulrich, Peter. 2008. Integrative economic ethics: Foundations of a civilized market economy. Cambridge: Cambridge Univ. Press.

Varey, Richard J., and Michael Pirson (eds.). 2014. Humanistic marketing. Humanism in business series. New York: Palgrave Macmillan.

von Kimakowitz, Ernst, Michael Pirson, Heiko Spitzeck, Claus Dierksmeier, and Wolfgang Amann (eds.). 2011. Humanistic management in practice. Humanism in business series. New York: Palgrave Macmillan.

Waligorski, Conrad P. 1990. The political theory of conservative economists. Lawrence: University of Kansas Press.

Walras, Léon. 1909. Elements of pure economics. Boston: Kluwer Academic Publishers.

Weber, Max. 1904. Die "Objektivität” sozialwissenschaftlicher und sozialpolitischer Erkenntnis. Archiv für Sozialwissenschaften und Sozialpolitik 19: 503-574.

Weber, Max. 1918. "Der Sinn der "Wertfreiheit" der soziologischen ökonomischen Wissenschaften." Logos 7.

Welsch, Wolfgang. 1988. Unsere postmoderne Moderne, 2nd ed. Weinheim: VCH.

Welsch, Wolfgang. 2002. Unsere postmoderne Moderne. 6. Aufl. Acta humaniora. Berlin: Akad.-Verl.

Werther, Willian B., and David Chandler, JR. 2005. Strategic Corporate Social Responsibility: Stakeholders in a Global Environment: Sage Publications.

Wieser, Friedrich F. v. 1884. Über den Ursprung und die Hauptgesetze des wirtschaftlichen Werthes: A. Hölder.

Young, Robert. 1986. Personal autonomy: Beyond negative and positive liberty. International series in social and political thought. London: Croom Helm. 